\title{
The sustainable worldwide offshore wind energy potential: A systematic review
}

Samira Keivanpour, Amar Ramudhin, and Daoud Ait Kadi

Citation: Journal of Renewable and Sustainable Energy 9, 065902 (2017);

View online: https://doi.org/10.1063/1.5009948

View Table of Contents: http://aip.scitation.org/toc/rse/9/6

Published by the American Institute of Physics

\section{Articles you may be interested in}

In search of the wind energy potential

Journal of Renewable and Sustainable Energy 9, 052301 (2017); 10.1063/1.4999514

Syngas production through biomass $/ \mathrm{CO}_{2}$ gasification using granulated blast furnace slag as heat carrier Journal of Renewable and Sustainable Energy 9, 053101 (2017); 10.1063/1.4993259

A probabilistic method for cost minimization in a day-ahead electricity market considering wind power uncertainties

Journal of Renewable and Sustainable Energy 9, 063301 (2017); 10.1063/1.4987037

Catalytic characteristics of pyrolysis volatile matter from biomass/biomass components on a novel Ni-based catalyst supported by iron slag

Journal of Renewable and Sustainable Energy 9, 063101 (2017); 10.1063/1.4985944

Effects of second-order wave forces and aerodynamic forces on dynamic responses of a TLP-type floating offshore wind turbine considering the set-down motion

Journal of Renewable and Sustainable Energy 9, 063302 (2017); 10.1063/1.5007893

A learning-based optimization of active power dispatch for a grid-connected microgrid with uncertain multi-type loads

Journal of Renewable and Sustainable Energy 9, 065901 (2017); 10.1063/1.4986388 


\title{
The sustainable worldwide offshore wind energy potential: A systematic review
}

\author{
Samira Keivanpour, ${ }^{1, a)}$ Amar Ramudhin, ${ }^{2, b)}$ and Daoud Ait Kadi ${ }^{2, c)}$ \\ ${ }^{1}$ The Department of Mechanical Engineering, Laval University, Quebec, Quebec GIV 0A6, \\ Canada \\ ${ }^{2}$ The Logistics Institute of University of Hull, Hull HU6 7RX, United Kingdom
}

(Received 7 June 2016; accepted 18 October 2017; published online 13 November 2017)

\begin{abstract}
The offshore wind industry is expanding rapidly around the world due to several factors enabling this source of renewable energy. Stronger wind resources in offshore areas, lack of social and geographical constraints related to onshore wind power, the evolution of technology, and increasing demand for electricity in coastal regions as a result of a massive increase in population are some of the factors favoring the use of wind energy. The assessment of the potential global capacity that considers the different economic, environmental, and social factors and the dynamics of market, policy, and technology are vital for estimating the competitiveness of offshore wind energy in the future energy profile. There are several studies and technical reports that evaluate the potential of offshore wind energy in different countries or regions. They used a different source of data, metrics, and quantitative approaches in appraising the potential offshore wind power capacity and its cost efficiency. The critical factors that have been considered are geographical, technical, economic, environmental, and social and market elements. This paper provides a systematic review for analyzing the studies that address the potential offshore wind energy around the world and published during the 2000-2016 period. This study highlights the key criteria for assessing the potential for offshore wind energy deployment and the related tools and methods. Published by AIP Publishing. https://doi.org/10.1063/1.5009948
\end{abstract}

\section{INTRODUCTION}

Access to a reliable source of energy without fluctuations in the fossil fuel market such as volatilities in price, demand, and supply and concerns about global warming are the key drivers for using renewable energy. According to Asif and Muneer (2007), the energy supply could become more vulnerable as a result of increasing global dependence on imported oil. Based on this reference, the global demand for oil is constantly growing, particularly with the growth trend of emerging economies such as China and India. The price of oil is also extremely volatile due to geopolitical factors, military conflicts, or extreme weather events. Jacobson (2009) reviewed nine electrical power sources (solar-photovoltaics, concentrated solar power, wind, geothermal, hydroelectric, wave, tidal, nuclear, and coal with carbon capture and storage technology) and new technology vehicles including battery-electric vehicles, hydrogen fuel cell vehicles, and flex-fuel vehicles. The author evaluated the combinations of energy sources and vehicle types and classified them according to four tiers. The result of this study revealed that wind energy as a source of power is the best one with respect to effects on global-warming-relevant emissions, air pollution, and energy security. Among renewable energy sources, wind power shows considerable growth. The global investment on wind power is $109 \$$ billion, which makes it one of the fastest emerging industrial segments in the world ("Wind in Numbers").

\footnotetext{
a)samira.keivanpour.1@ulaval.ca

b)A.Ramudhin@hull.ac.uk

c)Daoud.Aitkadi@gmc.ulaval.ca
} 
Esteban et al. (2011) explained that this growth is due to the availability of wind resources in comparison with solar or wave and the advanced technology is the result of long experience in sailing, milling, etc. Many coastal areas have very high energy needs. For example, 53\% of the US population lives in coastal areas and offshore wind farms in these zones can aid in meeting energy needs from nearby sources ("Offshore Wind Energy"). However, there are different economic, social, and environmental concerns that need to be considered. Rodrigues et al. (2015) presented the trends in offshore wind projects based on different characteristics such as country, capacity, number of turbines, water depth, grid connection technology, and costs. Based on this analysis, the offshore wind industry has had an average yearly growth of $36 \%$ since 2001 . The UK, with 26 projects, has $46 \%$ of the installed offshore wind capacity in Europe. Germany with 30\% and Denmark with 12\% are in second and third positions, respectively (Higgins and Foley, 2014).

Figure 1 shows the capacity of offshore wind projects that are commissioned or under construction in Europe and outside Europe based on LORC (Lindoe Offshore Renewables Center) data ("List of Offshore Wind Farms"). As presented, Germany and the UK are the leading countries in investment in the offshore wind market. However, the Asian countries are in a growth phase. Europe continues its development to install about $70 \mathrm{GW}$ by 2020 ("Global Wind Report," 2014).

According to Snyder and Kaiser (2009a), the quality of offshore winds with respect to the strength and the consistency and lack of conflicts with landowners are the motivations for the developers and government in Europe for developing offshore wind farms. Henderson et al. (2003) mentioned the market development in the energy industry as a driver for the development of offshore wind energy. Minimum shares for renewable energy for utilities and consumers in EU (European Union) countries like Belgium and Denmark and green certificate markets in countries such as Ireland and the Netherlands play an important role in the growth of the offshore wind energy in EU. Breton and Moe (2009) also mentioned the supporting policy and incentives by governments and EU and the decrease in the cost per megawatt hour by $50 \%$ in the last few years as the essential factors for growing offshore wind energy in Europe. Schwägerl (2016) explained that the cost deduction of offshore wind energy in Europe is due to industrialization and standardization of the production process of wind turbines and the large size of the new turbines for more efficiency.

The United States has also planned for developing and launching offshore wind farm projects and played a critical role in the market. The first wind turbines were installed close to three miles offshore Block Island, Rhode Island in August 2016 (Fehrenbacher, 2016). Kempton et al. (2007) assessed the potential of using offshore wind energy in Middle-Atlantic Bight for
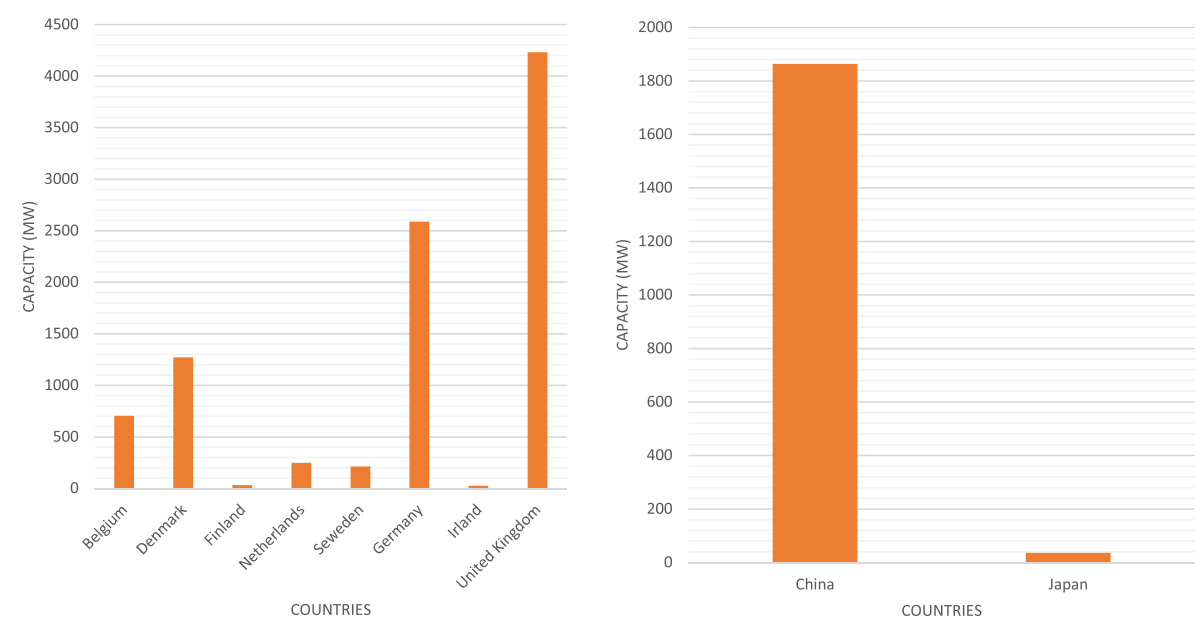

FIG. 1. The capacity of offshore projects commissioned or in progress. Left: in Europe; Right: Outside Europe; source of data: LORC (Lindoe Offshore Renewables Center) data ("List of Offshore Wind Farms"). 
supplying the energy demand in Massachusetts through North Carolina in the US. The authors explained that using offshore wind energy could reduce $\mathrm{CO}_{2}$ emissions by $68 \%$ that is the required reduction for climate stabilization.

The assessment of the potential global capacity that considers the different sustainability features including economic, social, and environmental factors is important in the estimation of the competitiveness of offshore wind energy in the future energy profile. In this paper, we aim to study research publications and technical reports that evaluate the potential of offshore wind energy in different countries or regions during the 2000-2016-period. Those studies used a different source of data, metrics, and quantitative approaches in appraising potential offshore wind power capacity and its cost efficiency. There is a lack of consistent conclusions about the criteria for capacity estimation and the reliable tools and methods for these estimates. Here, we take a step toward filling this gap by identifying the criteria for assessing the potential offshore wind energy capacity and reviewing the methods for analyzing this capacity.

The first issue in market deployment of offshore wind farms is offshore wind resources. The viability of offshore wind energy in a specific zone, the technical features, the geographical and spatial constraints, and economy of wind farms are crucial factors and indicate the feasibility of developing the offshore wind farms. The sustainability of the development takes into account the economic, environmental, and social factors. Economic factors include the economy of offshore projects, the effectiveness, and efficiency of the development and the other socio-economic impacts. The environmental factors include resource use and waste and emission management, and social factors comprise safety, community investment, and stakeholder's involvement. Moreover, different uncertain factors such as policy changes, technology evolution, or financial markets influence the offshore wind energy industrial chain. Therefore, the integrated approach for estimation of offshore wind potential should consider the flexibility of development to these uncertainties. In this paper, these three vital aspects, feasibility, sustainability, and flexibility, are considered in the literature to identify how these factors are accounted for assessing the potential offshore wind energy capacity and what are the methods for evaluating these aspects.

The rest of this paper is organized as follows: First, we deliver a literature review to highlight the key criteria for estimation of practical offshore wind energy and the related tools and methods. Then, we summarize this paper and explain the findings and the venues for future research.

\section{SYSTEMATIC REVIEW OF THE LITERATURE}

A systematic literature review is an effective tool for studying and analyzing a large amount of information and facilitating its management. The goal of a systematic literature review is to provide a comprehensive summary of the current literature relevant to a specific research question (Vázquez-Carrasco and López-Pérez, 2013; Rousseau et al., 2008; and Tranfield et al., 2003). The following research approach was conducted in this study:

Step 1: First of all, the review questions were defined. We reviewed the literature on offshore wind energy assessment around the world. A substantial number of offshore wind energy assessment studies are available in the literature although there is a lack of consistent conclusions about the key criteria for capacity estimation and the reliable tools and methods for these estimates. Three crucial aspects, feasibility, sustainability, and flexibility, were selected as integrated factor taxonomy to assess all technical, environmental, economic, and social factors as well as the capability to respond to the uncertain elements of market, technology, and policy. Hence, the following questions were addressed:

1. How are sustainability, feasibility, and flexibility factors accounted for when assessing the potential offshore wind energy capacity?

2. What are the methods for analyzing these factors?

3. What is the existing gap in the literature review, and how can we fill this gap?

Step 2: The relevant works including journal papers, conference papers, and technical and industrial reports were identified. For this aim, a search was carried out based on the following keywords (offshore wind energy potential, offshore wind energy/power assessment, offshore wind 
resource assessment). The two essential keywords "offshore wind/power" and "assessment/ estimation" are used together to narrow the screening results and more focused on the articles that cover the estimation of offshore wind potential. This search was done via bibliographic databases and scholar search engines. Filtering the literature based on the defined criteria is a key step to focus on high-quality information. An initial screening was performed to eliminate some references and select the target group of references. This step is a crucial step in the systematic literature review and has been done in several studies such as Kim et al., 2012 and Asdrubali et al., 2015. We also focused on the studies that were published during the 2000-2016 period.

Step 3: The second round of screening the literature was done to limit the collection of references by defining the quality criteria. We excluded the news, posters, abstracts, or any documents that do not include a scientific approach for estimation of offshore wind potential to secure the validity of the study. In a scientific approach, a problem is first defined and then the relevant data or experiments are used to construct and evaluate the hypotheses to solve it. We looked for studies that defined the goals and assumptions for the assessment of offshore wind energy clearly. These studies needed to provide the criteria for estimates and the related parameters and present the methods and tools for assessment precisely. Furthermore, the metrics such as impact factors, the reputation of the publishers, and the number of citations are considered for assessing the quality of the journals, conference proceedings, or the relevant industrial or governmental sectors' publications to improve the reliability of the literature review.

Step 4: The information related to each article was entered in an Excel sheet for organizing and database management.

Step 5: The analysis of the literature review was performed to obtain and classify the key criteria and factors for estimation of offshore wind energy in the three categories of feasibility, sustainability, and flexibility, and then, the utilized tools and methods are assessed.

Step 6: Finally, the results and findings are discussed, and the research outline is recommended.

A total of 29 articles were obtained. Table I shows the articles, source, authors, publication year, and the geographical region that the article was considered. The preliminary results including the area under study and the number of studies per publication year are shown in Figs. 2 and 3, respectively. NREL (National Renewable Energy Laboratory) Energy, Renewable Energy, and Energy Policy are the top publications for this area of research and cover $45 \%$ of the articles. Europe (including Denmark, Scotland, and North Sea) with $24 \%$ has more studies considering the geographic region of the studies. Worldwide with $20 \%$ and US and Korea with $14 \%$ are in second and third places. The number of published works in $2012-2014$ is considerable (45\% of references).

\section{THE POTENTIAL FACTORS FOR ASSESSMENT}

The content analysis of the studies reveals that there is no common point of view for classification of the key factors for assessing potential offshore wind farm deployment. For example, the distance to the shore is considered as an economic factor or geographic factor or social factor in different articles. Exclusion of the natural protected areas is considered as an environmental consideration or geographical or spatial limitation. In this section, a classification scheme was provided to review the literature on estimation of potential offshore wind energy. The key aspects of the sustainable and robust development of offshore wind energy are considered for this classification.

This classification has the objective of delivering the pertinent factors that would support developing an appropriate approach to sustainable global spatial planning of offshore wind energy. This taxonomy is based on the feasibility, sustainability, and flexibility of offshore wind energy planning. The feasibility aspect covers the viability of offshore wind energy in a specific zone and includes the technical features, the geographical and spatial constraints, and the economic aspects of offshore wind energy development. In spite of providing an estimation of offshore wind potential, feasibility aspects do not cover the environmental and social aspects that reflect the sustainability of the assessment and the opportunities and constraints of local development and socio-economic characteristics. Hence, we reviewed the literature to find how 
TABLE I. Studies analyzing the offshore wind energy potential.

\begin{tabular}{|c|c|c|}
\hline Publication & Studies (Authors, Publication year) & Region under study \\
\hline Proceedings of European Wind Energy Conference. & Yamaguchi et al. (2004) & Japan \\
\hline \multirow[t]{3}{*}{ NREL (National Renewable Energy Laboratory) } & Schwartz et al. (2010) & US \\
\hline & Arent et al. (2012) & Global \\
\hline & Musial and Butterfield (2004) & US \\
\hline EEA (European environment energy) report & Swart et al. (2009) & Europe \\
\hline Offshore Wind Energy Research Project & Barthelmie et al. (2002) & Europe \\
\hline \multirow[t]{3}{*}{ Energy } & Hong and Möller (2011) & China \\
\hline & Möller et al. (2012) & Denmark \\
\hline & Oh et al. (2012a) & Korea \\
\hline \multirow[t]{4}{*}{ Renewable Energy } & Oh et al. (2012b) & Korea \\
\hline & Kim et al. (2013) & Korea \\
\hline & Li (2000) & Hong Kong \\
\hline & Dvorak et al. (2010) & US \\
\hline \multirow[t]{2}{*}{ Renewable and Sustainable Energy Reviews } & Lee et al. (2013) & Korea \\
\hline & O'Keeffe and Haggett (2012) & Scotland \\
\hline Applied Energy & Gao et al. (2014) & Hong Kong \\
\hline Proceedings of the National Academy of Sciences & Lu et al. (2009) & Global \\
\hline Ecofys Report & Hoogwijk and Graus (2008) & Global \\
\hline Ocean \& Coastal Management & Fetanat and Khorasaninejad (2015) & Iran \\
\hline Energy Conversion and Management & Wu et al. (2016) & China \\
\hline \multirow[t]{3}{*}{ Energy policy } & Jongbloed et al. (2014) & North Sea \\
\hline & Schillings et al. (2012) & North Sea \\
\hline & Möller et al. (2011) & Europe \\
\hline Power Engineering Society Summer Meeting, IEEE & Ackermann et al. (2001) & Europe \& Global \\
\hline Carbon Trust & Govindji et al. (2014) & Japan \\
\hline Marine Technology Seminar & Chiang et al. (2003) & Malaysia \\
\hline Geophysical Research Letters & Kempton et al. (2007) & US \\
\hline Dtu International Energy Report & Karlsson et al. (2014) & Global \\
\hline Applied Geography & Archer and Jacobson (2013) & Global \\
\hline
\end{tabular}

these aspects are considered in the references. Different uncertain factors such as policy changes, technology evolution, or financial markets influence the offshore wind energy industrial chain. The holistic approach for estimation of offshore wind potential should include these dynamics via certain scenarios. Therefore, we considered flexibility as the third group of essential factors in estimating offshore wind energy development. Figure 4 shows the taxonomy that

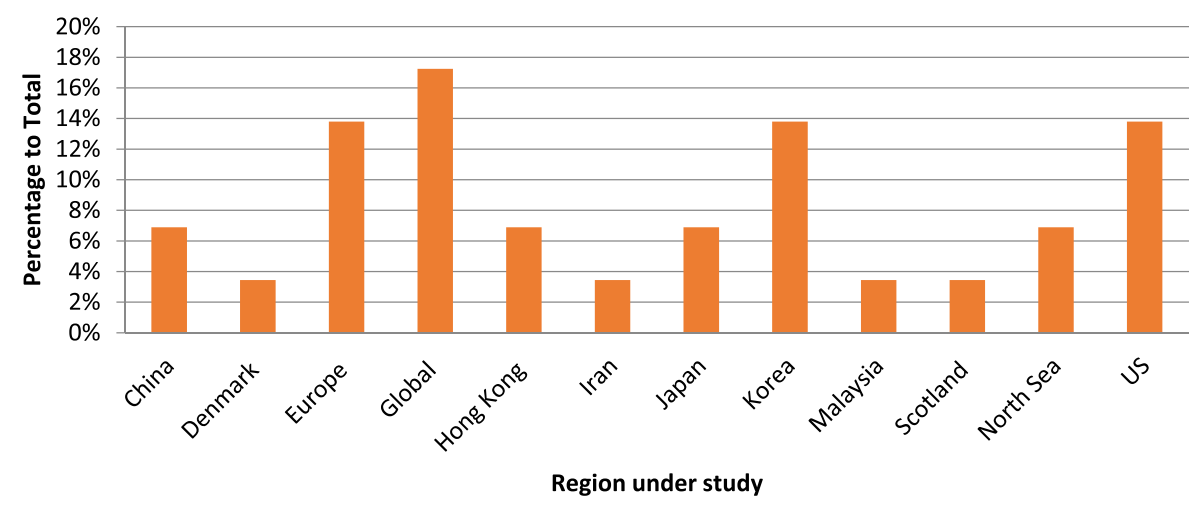

FIG. 2. Geographic region under study. 


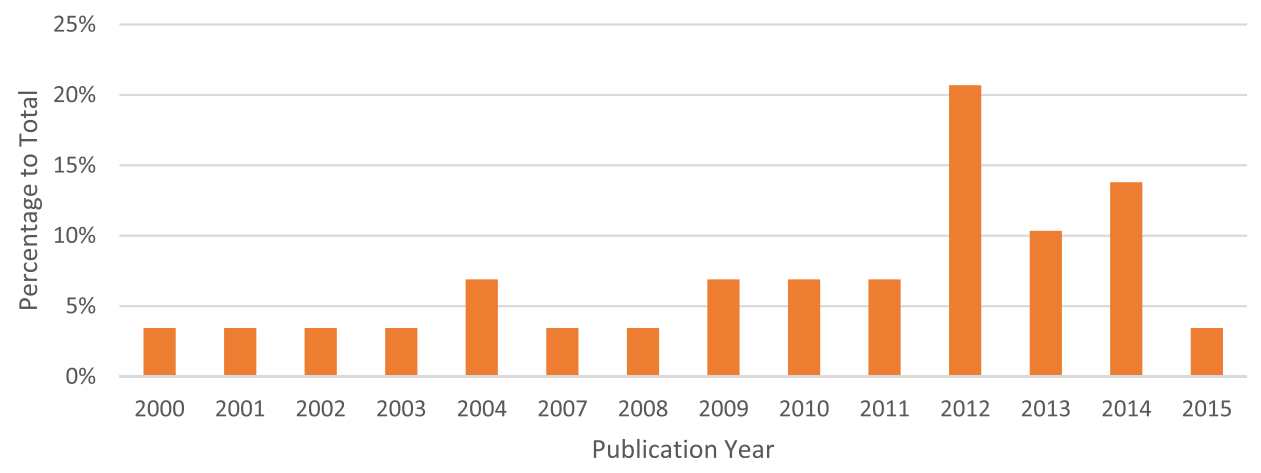

FIG. 3. Number of publications per year.

reflects the sustainability and resilience of the estimation. Based on this taxonomy, we identified eight categories of factors that are essential for estimating offshore wind potential. Each of these factors imposes limitations or constraints for wind farm development and restricts the potential areas. Considering all criteria due to database limitations is difficult. However, for obtaining a robust and sustainable planning, they cannot be neglected. In Secs. III A-III C, these eight categories of factors are explained. Table II shows the summary.

\section{A. Feasibility aspect}

The studies and projects that address potential offshore wind energy in a specific zone consider the viability of the offshore wind farm. The uncertainty regarding zone level wind resource estimations, energy predictions, ground conditions, metocean data, and cost of energy ("Pre-Feasibility Study," 2015) leads to the need for a systematic feasibility study for offshore wind energy assessment. The technical, geographical, and economic aspects are three crucial elements in the feasibility assessment.

\section{Technical factors (theoretical potential)}

The feasibility for the operation of offshore wind energy depends on the suitable wind conditions in the area (Mostafaeipour, 2010). Feasible wind resources in the offshore areas are the theoretical potential considering the natural and climate parameters (Hoogwijk et al., 2004 and Hoogwijk and Graus, 2008). The wind resource is projected via satellite measurements and

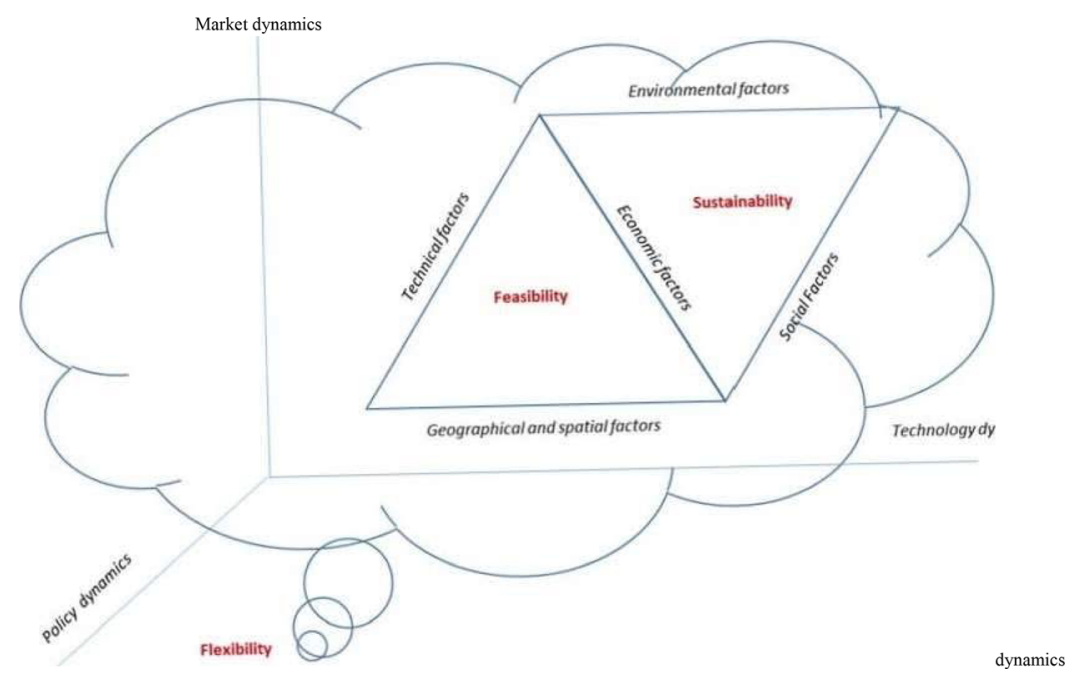

FIG. 4. Integrated offshore wind energy assessment. 
TABLE II. The essential factors in the estimation of the potential offshore wind energy.

\begin{tabular}{|c|c|c|c|c|c|c|c|c|}
\hline \multirow[b]{2}{*}{ Studies (authors, publication year) } & \multicolumn{8}{|c|}{ Factors } \\
\hline & Technical & $\begin{array}{l}\text { Geographic } \\
\text { and Spatial }\end{array}$ & Economic & Social & Environmental & Market & Policy & Technology \\
\hline Ackermann et al. (2001) & $*$ & & & & & & & \\
\hline Archer and Jacobson (2013) & $*$ & * & & & $*$ & & & \\
\hline Arent et al. (2012) & $*$ & * & & & $*$ & & & $*$ \\
\hline Barthelmie et al. (2002) & $*$ & & & & & & & \\
\hline Chiang et al.(2003) & $*$ & & & & & & & \\
\hline Dvorak et al. (2010) & $*$ & $*$ & & & & & & \\
\hline Fetanat and Khorasaninejad (2015) & $*$ & & $*$ & $*$ & $*$ & $*$ & $*$ & \\
\hline Gao et al. (2014) & $*$ & & $*$ & & & & & \\
\hline Govindji et al.(2014) & $*$ & $*$ & $*$ & & & $*$ & $*$ & $*$ \\
\hline Hong and Möller (2011) & $*$ & $*$ & $*$ & & & $*$ & $*$ & \\
\hline Hoogwijk and Graus (2008) & $*$ & $*$ & $*$ & $*$ & & & & \\
\hline Jongbloed et al. (2014) & $*$ & $*$ & $*$ & & $*$ & & & \\
\hline Karlsson et al. (2014) & $*$ & $*$ & $*$ & & & & & \\
\hline Kempton et al. (2007) & $*$ & & & & & & & \\
\hline Kim et al. (2013) & $*$ & $*$ & $*$ & & & & & \\
\hline Lee et al. (2013) & $*$ & & & & & & & \\
\hline Li (2000) & $*$ & & $*$ & & & $*$ & $*$ & \\
\hline Lu et al. (2009) & $*$ & $*$ & & & & & & \\
\hline Möller (2011) & $*$ & $*$ & $*$ & & & & & \\
\hline Möller et al. (2012) & $*$ & $*$ & $*$ & & & & & \\
\hline Musial and Butterfield (2004) & $*$ & $*$ & $*$ & & & & & $*$ \\
\hline O'Keeffe and Haggett (2012) & $*$ & & $*$ & $*$ & & & $*$ & \\
\hline Oh et al. (2012a) & $*$ & & & & & & & \\
\hline Oh et al. (2012b) & $*$ & & & & & & & \\
\hline Schillings et al. (2012) & $*$ & $*$ & $*$ & & $*$ & & & \\
\hline Schwartz et al. (2010) & $*$ & $*$ & & & $*$ & & & \\
\hline Swart et al. (2009) & $*$ & $*$ & $*$ & & $*$ & $*$ & $*$ & $*$ \\
\hline Wu et al. (2016) & $*$ & & $*$ & $*$ & $*$ & & $*$ & \\
\hline Yamaguchi et al. (2004) & $*$ & $*$ & $*$ & $*$ & & & & \\
\hline
\end{tabular}

ocean bathymetry data (Govindji et al., 2014). Simulated winds by numerical weather prediction models are also common techniques for wind resource assessment.

According to the physics of the power of wind, the air density and wind speed are two essential parameters in estimating wind energy resources. Air density is a function of altitude, temperature, and other parameters. Hence, the wind speed at the hub level [usually at a height of $90 \mathrm{~m}$ above the surface (Schwartz et al., 2010)] is used for estimating wind resources. Furthermore, soil mechanics, extreme waves, wake effects, icing impacts, and lightning are also important technical parameters that affect the design of wind turbines in offshore areas. The offshore environment imposes some technical and construction challenges based on metocean, seabed topography, and geological conditions (Zhixin et al., 2009 and Elliot et al., 2012). According to Elliot et al. (2012), typical wind conditions such as wind speed, direction, and intensity or ocean conditions such as average wave height, period, and tides could affect technology and facility design, operation planning, and performance monitoring. Marine subsurface conditions such as ocean depth temperature, marine growth, and seafloor scour could affect operation facility design. Also, extreme conditions such as extreme wind gusts, hurricanes, lightning, and earthquakes also affect energy projection, design, operations, and performance of offshore wind farms. 
Bathymetry data are also essential factors in the estimation of the theoretical potential wind resources. The monopoles and gravity foundations are used in shallow water (depth $<30 \mathrm{~m}$ ). Tripod and jackets could be used for $30 \mathrm{~m}<$ depth $<60 \mathrm{~m}$, and for deep water, the floating structures are appropriate (Schwartz et al. 2010).

\section{Geographical and spatial factors}

Offshore wind resources seem to be ample; however, geographical and spatial planning are factors that significantly reduce the theoretical potential (Möller, 2011). According to this reference, shipping is a significant competitor for the offshore zones. Shipping track databases can determine the maritime traffic and shipping density per square kilometer and can be used to exclude high maritime traffic areas (Arent et al., 2012). Based on Arent et al. (2012), shipping density is measured in kilometers of tracks per square kilometer and can be classified into three categories: $0-3,5-15$, and $>15 \mathrm{~km}$ per $\mathrm{km}^{2}$. Visibility from the coast, military areas, oil and gas exploration, and tourist zones (usually coastal areas with high population) should be excluded (Swart et al., 2009). Hong and Möller (2011) mentioned shipping lanes and submarine cables; the path of the Black-faced Spoonbill (Platalea minor) and visibility are spatial constraints for offshore wind energy zones. They considered a one-km shield for shipping lanes, $500 \mathrm{~m}$ for cables and pipelines, $3 \mathrm{~km}$ buffer for the bird path, and $8 \mathrm{~km}$ from all coasts for visibility for studying offshore wind potential in China's exclusive economic zone. Hong and Möller (2011) considered up to $3.7 \mathrm{~km}$ buffers for shipping, $0.5 \mathrm{~km}$ for cables and pipelines, $0.5 \mathrm{~km}$ for oil and gas platforms, $5 \mathrm{~km}$ buffer for birds, $19 \mathrm{~km}$ for visibility, $5 \mathrm{~km}$ for nature conservation, and the outside of defense and marine archaeology as the spatial constraints. Swart et al. (2009) emphasized that spatial planning is essential for guiding the suitable use of available offshore areas. According to the authors, for the regions up to $10 \mathrm{~km}$ from the coast, the wind farms can be seen from the coast. However, this rule of thumb could be different in different countries. For example, In the Netherlands, it is forbidden to build wind farms within $22 \mathrm{~km}$ from coasts due to the visual impacts. Hence, only $4 \%$ of offshore areas in the $0-10 \mathrm{~km}$ range might be feasible for development (Swart et al., 2009). The visual impact of the offshore wind turbine from the coastlines is also considered in the assessment of Korean offshore wind energy (Kim et al., 2013). The designers consider this constraint in order to avoid any future public complaints.

\section{Economic factors}

According to Hoogwijk and Graus (2008, p. 6), "the market potential is the total amount of renewable energy that can be implemented in the market taking into account the demand for energy, the competing technologies, the costs and subsidies of renewable energy sources, and the barriers." Govindji et al. (2014) considered energy supply and demand electricity market, regional energy supply and demand, and existing and pipeline projects as the areas of market study for appraisal of offshore wind energy. Yamaguchi et al. (2004) emphasized the role of estimation of the offshore wind areas around the supply areas of electricity service providers due to the demand and the grid network readiness for integration. Fetanat and Khorasaninejad (2015) also considered proximity to the area of electric demand and proximity to power transmission grid as the criteria for assessing offshore wind site candidates. These proximities could decrease the total costs of operations.

Swart et al. (2009) calculated the economically competitive potential based on the forecasted costs of developing wind farms in 2020 and 2030 for European offshore areas. They compared generation cost forecasts with projected electricity tariffs and average production costs of electricity in 2020 and 2030. They considered cost as a function of water depth and distance from the coast. Fetanat and Khorasaninejad (2015) considered the commercial feasibility of the sites, local economic benefits, and cost-benefit analysis of the renewable energy as the economic aspects of the assessment. Hong and Möller (2011) calculated the cost based on the turbine, foundation, grid, operation and maintenance, and investment cost. The authors estimated the turbine cost as a function of turbine size, the cost of foundation as a function of 
water depth, the cost of grid networks as a function of subsea cost distance and distance to land, and the operation cost as a function of distance to the harbor.

\section{B. Sustainability aspect}

The sustainability aspect includes three performance measurement systems: economic, environmental, and social performance. Based on the definition of the economic sustainability in the business context ("economic sustainability"), the economic aspect involves using the various assets and capital investments in offshore wind energy efficiently to allow it to continue functioning productivity and profitability over time. This aspect addresses the economy of wind projects and the cost effectiveness. The other aspect of economic sustainability is socioeconomic features including improving employment and economic opportunities and effective collaboration among stakeholders to facilitate and expedite the offshore wind farm development and eliminate the barriers and challenges.

The environmental performance includes resource use, waste and emission management, and social performance. The life cycle approach is needed to evaluate the sustainability performance of offshore wind energy development. A life cycle approach aims to identify the impacts of decisions at each step of product development to have a trade-off analysis based on the impacts on the economy, the environment, and society. Life cycle assessment (LCA) is an ecological analysis tool that considers all the processes of a product and its component from the beginning of the life cycle to the end of life or disposal (Hauschild, 2005). Finkbeiner et al. (2010) explained the challenges of the implementation of the sustainability concept in the organizations. The authors reviewed the life cycle sustainability assessment methods. They mentioned that LCA is available for the environmental dimension of sustainability. However, it is still needed to define reliable measures and indicators for economic and social aspects. Recently, there have been several studies that address the LCA of wind energy. Bonou et al. (2016) examined the LCA of offshore and onshore wind turbines in Europe. The authors mentioned that the impacts of offshore wind farms are higher due to the need of more materials with high impacts for building the infrastructures. Garrett and Rønde (2013) provided a state of the art literature regarding LCA of wind turbines. Guezuraga et al. (2012) also provided the LCA of wind turbines and explained that the higher energy consumption of wind turbines is linked to the manufacturing phase, which contributes to $84.4 \%$ of the total life cycle.

The other aspect in the sustainable development approach is analyzing the social impacts including safety, community investment, and stakeholder's involvement. According to Benoit (2010), the Social LCA (SLCA) refers to the evaluation of the actual and potential social and socio-economic impacts of the products and services along with their life cycle. In contrast to environmental metrics, social metrics are tough to be quantified (Swarr, 2009), and the assessment of the social impacts raised new challenges for LCA database developers (Norris, 2006).

Considering the trade-off analysis of economic, environmental, and social impacts of offshore wind development makes the assessment a sustainable evaluation. We already addressed and discussed the economy of wind farm projects in part 4.1.3. The socio-economic feature should be taken into account via social and environmental aspects. Hence, we examined the social and environmental sustainability factors in this section.

\section{Social factors}

As mentioned before, the first social factor that has been considered in offshore wind energy is the public opposition to the visibility of the wind farms from the coastlines. Yamaguchi et al. (2004) considered the areas with fishery rights and port areas as the social aspects in the estimation of the potential offshore wind farms. Fetanat and Khorasaninejad (2015) also defined community acceptance, the interest of social groups, and aesthetic considerations (view from shorelines) as social factors for evaluation of sites in Iran. However, the total impacts of the development on communities and the public should be evaluated to reveal the trade-off analysis as to its pros and cons. The social impacts of an offshore wind farm include the effect on the security of energy, social welfare, local development, job creation, and 
possible health and environmental concerns (Kaldellis, 2005 and Wüstenhagen et al., 2007). Business development in the port area and preserving harmony in the community, the impacts on improving local fishing and tourism and, on the other side, concerns related to bird and marine life, potential toxic impacts and air quality are the main issues that influence the public's perceived values regarding offshore wind power.

\section{Environmental factors}

Protected areas should be excluded from potential offshore areas. Natura 2000 is a network of wildlife protection zones in the European Union. According to Swart et al. (2009), while it is not prohibited to place wind farms on "Natura 2000" sites, these areas could be considered as the restricted areas implied by biodiversity protection. Fetanat and Khorasaninejad (2015) considered the noise impact, closeness to migratory paths for birds, and proximity to migratory paths for marine life as the environmental criteria for offshore wind farm site selection. Snyder and Kaiser (2009b) stressed that siting offshore wind farms near nesting sites for seabirds might be hazardous. From the viewpoint of conserving biodiversity, it is essential for developers to exclude areas considered habitat for threatened or endangered species.

The natural disaster hazardous areas should be excluded from the potential areas. The possibility of catastrophic events such as strong earthquake and tropical cyclones should be taken into account in feasibility studies. Few studies considered the risk of natural disasters in their estimation. Hong and Möller (2011) mentioned that the detailed analysis of the influence of tropical cyclone risks in China's exclusive economic zone should be addressed. However, the authors explained that the risk analysis of hazardous natural events is beyond the scope of their study. Li (2000) considered extreme conditions of wind, wave, and joint probability of extreme wind and waves for a feasibility study of offshore wind energy in Hong Kong. According to the author, based on the closeness of typhoon occurrence (on average every 3.3 years) in the territory of the offshore sites, wind turbines and foundation should be designed taking extreme weather events into account.

\section{Flexibility aspect}

Different uncertain factors influence the offshore wind energy industrial chain such as policy changes, technology evolutions, and financial markets. The interaction of demand and supply uncertainties and other business environmental factors contribute to the complexity of offshore wind energy development. Zhao et al. (2015) studied the flexibility of the wind power industry in China considering industry technology, market competition, and policy changes. Li et al. (2015) also assessed the flexibility of the wind energy chain via seven factors: structural flexibility, production flexibility, operational flexibility, technological flexibility, development flexibility, construction flexibility, and policy flexibility. In this study, we selected the three dimensions of technology, market, and regulation changes as the key drivers of dynamics in the offshore wind industry and evaluated how scholars consider this dynamic in their assessment.

\section{Market}

The Levelized Cost of Energy (LCOE) is a primary indicator for calculating the cost of offshore wind energy during the whole life cycle. It is defined based on the total cost of developing and operating an offshore site divided by the total electricity during the lifetime of a wind farm, properly discounted. According to Levitt et al. (2011), the following items should be considered in this calculation:

- Capital Costs: the total cost of developing an offshore wind farm

- Operating Costs: total cost of operation and maintenance,

- Discount rate: the interest rate applied in discounted cash flow analysis to calculate the present value of future cash flows (Investopedia, 2017).

- Net Capacity Factor: considering the losses and availability to find the net annual energy production,

- Financial structure: considering the debt term, the term of power purchase agreement, etc. 
In addition, tax and policy inputs, price escalator, inflation of the capital, and operating cost should also be considered. All these elements change with the dynamics of the market context.

Market growth and technological evolution play an important role rather than resource accessibility (Swart et al., 2009). According to Swart et al. (2009), the wind turbine market is an international market that is dominated by a few manufacturers. The entry of new players into the market and more competition could affect the costs and create more opportunities for offshore wind energy development.

\section{Policy}

Governments play an essential role in the renewable energy sector. The plan and policy provided by local governments can shape the business structure. The mechanisms for tax credits and subsidies have impacts on investment and development of wind power zones. Moreover, the other role is supporting local suppliers and business sectors to lead the growth and competition in the offshore wind energy market. Collaboration between governments and different industrial parties can facilitate and expedite the development process and remove the barriers and challenges. Fetanat and Khorasaninejad (2015) considered the integration of the national energy policy and renewable energy alternative and the consensus of leaders regarding offshore wind energy as the policy criteria regarding federal, state, and local agencies. The feed-in tariff (FIT) is a finance mechanism for offshore wind energy sections. This policy plays a key role in the growth of offshore wind site development due to the high cost of this type of renewable energy. Hong and Möller (2011) assessed the impact of FIT on the economic potential of offshore wind in China. The authors considered different scenarios based on the FIT variation. They found that there is a growth rate in economic potential as a result of increasing FIT from 80 to $100 € / \mathrm{MWh}$ but decay to $50 \%$ and $28 \%$ from 120 to $140 € / \mathrm{MWh}$ for a $5 \mathrm{MW}$ scenario in 2010 and an $8 \mathrm{MW}$ scenario in 2020. By further escalating FIT from 140 to $160 € / \mathrm{MWh}$, the growth rate of economic potential decreases to 5\%,6\%, and 7\% in 2010, 2020, and 2030, respectively. Once FIT rises to $160 € / \mathrm{MWh}$, it will be too expensive to develop offshore wind energy further. Therefore, there would be an optimal amount of FIT in the offshore projects.

The role of policy makers is also vital in the development of the wind energy. Yi and Feiock (2014) studied the drivers and competing forces of the renewable energy development in the USA. The results of this study show the influence of the regulatory institutions, the party affiliations of the governor and legislators, and the professionalism of the legislature on the development of the renewable resources in addition to the role of the different policy instruments. Zhang et al. (2014) also investigated the role of politician and leaders in the development of the renewable energy resources including wind and solar energies. The authors explain that the government background of the managers in the wind energy companies could decline the effects of the government subsidies.

\section{Technology}

Technology evolution in rated power, rotor diameter, hub height, capacity factors, array efficiency, and availability should be considered for estimation of offshore wind energy. Zhixin et al. (2009) studied the key technologies of the offshore wind farm and classified them into eight categories: foundations, site selection, wind measurement, wind turbines, hoisting, electrical transmission, and operation. These technologies affect the configuration of wind farms, operations, and performance. Sun et al. (2012) also provided a review of offshore wind power technology development. They studied support structure technology, layout optimization, protection issues, and environmental concerns. Higgins and Foley (2014) also studied technology development via five main components of an offshore wind turbine, foundation, tower, blades, drivetrain, grids, and substation. Another key issue in wind energy operation is addressing the balance between generation and consumption. Based on the variability of wind power, there is a need for energy storage. Storage could provide secure energy in the electric load and help in voltage stabilization. The new technology offers different solutions such as pumped hydro for large-scale energy storage ("Pumped hydro offers storage solution," 2014). Figure 5 shows the 

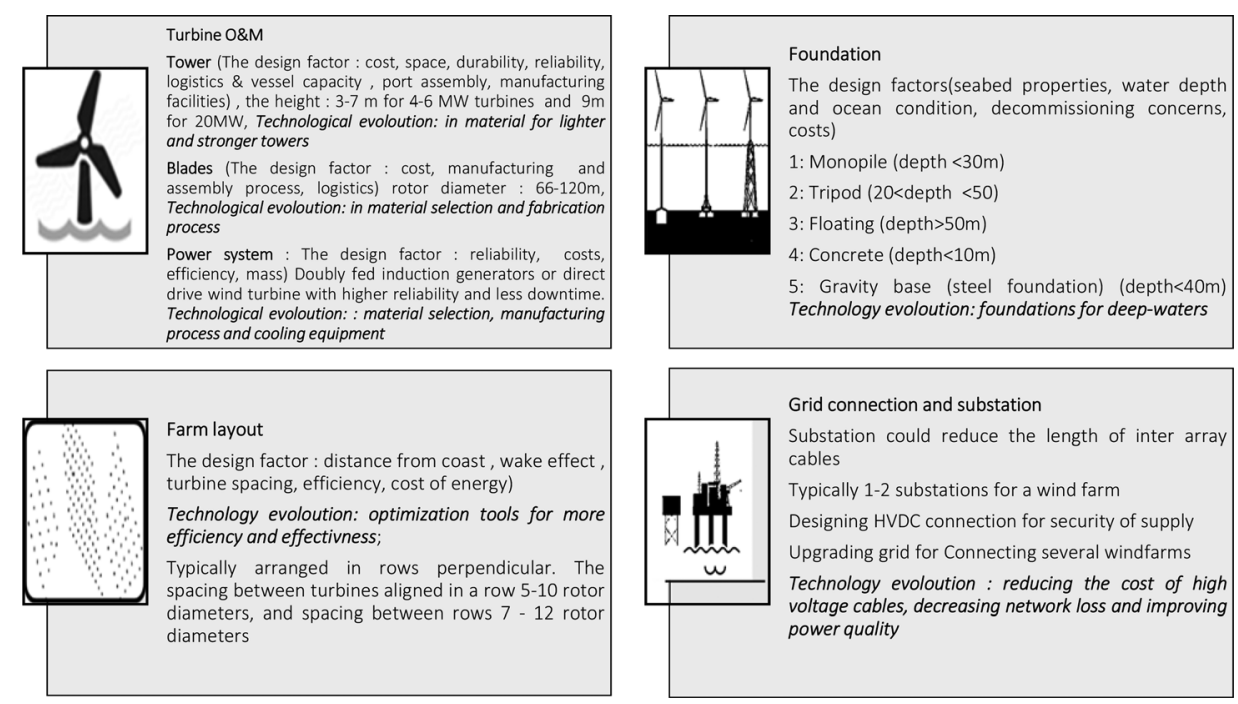

FIG. 5. Key elements of the offshore wind farm configuration and the sources of technological changes [Zhixin et al., (2009); Sun et al., (2012); and Higgins and Foley (2014)].

key elements of the wind farm configuration and the sources of technological changes that could influence the development of offshore wind energy.

Govindji et al. (2014) mentioned that the realistic offshore wind potential in Japan could be estimated using fixed-bottom turbines and the remainder using floating technology. The capital investment for each $\mathrm{kW}$, the fixed and variable costs of operation, and maintenance and capacity factor are the aspects that will be changed by technology evolution (Arent et al., 2012). Swart et al. (2009) made projections regarding the technological and economic development of the wind turbine including rated power, rotor diameter, and hub height in 2020 and 2030 to have an estimation of potential offshore wind energy. Musial and Butterfield (2004) mentioned that growth rates, learning curve effects, and improvements in operational proficiency and improvements in technology are important elements in the projection of costs and consequently the potential of offshore wind farm development. Musial and Butterfield (2004) also stated that the possibility of deep-water offshore wind development is practical with an active research and development agenda involving close collaborations between the oil and gas industry and the offshore wind community. Their analysis shows that new technology can be developed that could make floating wind turbines cost-effective, at energy costs as low as $\$ 0.051 / \mathrm{kWh}$ considering adequate volume production.

The other technological aspects include turbine efficiency, maintenance, and operation issues and the wind farm layout design parameters. Fetanat and Khorasaninejad (20 satellite data 5) considered the availability of wind resources, the capacity of local actors for installation and maintenance, reviewing and analyzing potential sites, and sufficient time for a feasibility study as the technical criteria for evaluation of offshore wind energy. Hong and Möller (2011) mentioned the efficiency of the turbine rotor, turbines downtime for maintenance, electrical network losses, and layout efficiency as practical factors for estimating offshore wind energy in China.

\section{METHODS AND TOOLS FOR ASSESSMENT}

In this section, we review the methods and tools that are utilized in the references for the assessment of offshore wind energy potential. These methods and tools include the approach for the analysis of meteorological data and geographically based methodology for assessing wind resources that mainly address the feasibility aspect and the optimization approach for selection of potential areas based on the different criteria of sustainability and flexibility aspects. 
The survey analysis based on the previous studies and case study approach for a wind farm site are also used in the articles that are surveyed. Some studies focus on the secondary data from the previous researches, technical reports, or case study analysis to provide discussion regarding the opportunities for and barriers to offshore wind energy potential. Karlsson et al. (2014) reviewed worldwide forecasts of wind power development in scenarios from different energy system models and recommended the required conditions to enhance wind energy expansion in the future. Ackermann et al. (2001) focused on Europe offshore projects, the opportunities, and challenges to discuss the worldwide potential. O'Keeffe and Haggett (2012) studied the case of the fourth and fifth offshore wind farm in Scotland to assess the barriers to offshore development.

Hoogwijk and Graus (2008) reviewed the different methodologies and the results of the long-term technical potential of renewable energy sources. The other approaches for the assessment of offshore wind energy are life cycle assessment and cost-benefit analysis. For example, Musial and Butterfield (2004) used the cost of energy projections, for the assessment of offshore wind energy in the US. As the life cycle assessment approaches only focus on the environmental impacts of offshore wind energy development and ecological footprints of the different stages of the life cycle, we excluded these studies in this review. In this part, we mainly focus on the most common approaches that are utilized in the references. Table III summarizes these approaches.

\section{A. Tools and method for assessing the feasibility aspect}

\section{Mesoscale model}

Mesoscale models are numerical weather prediction methods, and in combination with the other approaches like microscale downscaling, they are used for wind resource assessment and short term prediction (Vincent et al., 2017).

TABLE III. The assessment tools and methods used in the references.

\begin{tabular}{|c|c|c|c|c|}
\hline Studies (authors, publication year) & $\begin{array}{l}\text { Mesoscale } \\
\text { model }\end{array}$ & $\begin{array}{l}\text { Geographical information } \\
\text { system (GIS) }\end{array}$ & $\begin{array}{l}\text { Statistical } \\
\text { methods }\end{array}$ & $\begin{array}{l}\text { Optimization } \\
\text { approach }\end{array}$ \\
\hline Arent et al. (2012) & * & $*$ & & \\
\hline Archer and Jacobson (2013) & * & $*$ & & \\
\hline Chiang et al. (2003) & & & * & \\
\hline Dvorak et al. (2010) & $*$ & & $*$ & \\
\hline Fetanat and Khorasaninejad (2015) & & & & $*$ \\
\hline Gao et al. (2014) & & & & $*$ \\
\hline Govindji et al. (2014) & $*$ & $*$ & & \\
\hline Hong and Möller (2011) & & $*$ & & \\
\hline Jongbloed et al. (2014) & & & & $*$ \\
\hline Kempton et al. (2007) & & & $*$ & \\
\hline Kim et al. (2013) & & & & $*$ \\
\hline Lee et al. (2013) & & & $*$ & \\
\hline Li (2000) & & & $*$ & \\
\hline Lu et al. (2009) & & & $*$ & \\
\hline Möller (2011) & & $*$ & & \\
\hline Möller et al. (2012) & & $*$ & & \\
\hline Oh et al. (2012a) & & & $*$ & \\
\hline Oh et al. (2012b) & & & $*$ & \\
\hline Schillings et al. (2012) & & & & $*$ \\
\hline Schwartz et al. (2010) & $*$ & $*$ & & \\
\hline Swart et al. (2009) & * & $*$ & & \\
\hline Wu et al. (2016) & & & & $*$ \\
\hline Yamaguchi et al. (2004) & $*$ & $*$ & & \\
\hline
\end{tabular}


The mesoscale modeling approach uses a set of equations of a numerical model that reveals the evolution of the atmosphere. Usually, wind, temperature, pressure, and moisture content are used as the model parameters. A three-dimensional grid with meteorological parameters represents the behavior of the atmosphere. The grid size and resolution determine the precision of the model. The approximation of the non-hydrostatic Reynolds-averaged basic equations could be performed by numerical methods based on the initial condition and the latest information ("Mesoscale Model," 2015). Hence, the simulation can show the forecast of the atmosphere state based on the latest observation dataset. The verification of the model could be done based on the observation dataset at different meteorological stations.

The next generation of this modeling approach uses a data assimilation system and a software architecture for facilitating parallel computation. The model covers a wide range of meteorological applications across scales from tens of meters to thousands of kilometers (WRF website).

Yamaguchi et al. (2004) used a regional atmospheric modeling system that includes the motion equation, thermodynamic equation, and mass continuity equation. For running a simulation model, a grid resolution of $2 \mathrm{~km}$ was selected to cover the region under study. Archer and Jacobson (2013) utilized a global model including Mesoscale and the Ocean Model that simulates climate, weather, and air pollution. It should be noted that today, there are major tools for global wind estimation. Global Wind Atlas ("Global Wind Atlas") is one of these tools that provide wind resource data accounting for high-resolution effects and use microscale modeling to capture small scale wind speed variability.

\section{Geographical information system (GIS)}

GIS models aim to analyze, organize, and present the spatial or geographical data. According to Schwartz et al. (2010), GIS models include offshore wind resource data such as wind speed, water depth, and distance from the shore as well as the information related to state administrative areas to analyze the zones based on the different scenarios. The GIS database could be expanded to include the other parameters such as wave power density, ocean currents, and technical parameters. Yamaguchi et al. (2004) used GIS models for considering social and economic criteria for estimation of the supply curve of the offshore wind energy in Japan. Hong and Möller (2011) applied GIS models to address the impact of each spatial constraint and the different scenarios on marginal costs of offshore wind power development in China's exclusive economic zone.

\section{Statistical methods}

In addition to physical resource modeling that uses climatological data such as mesoscale models, statistical methods could be applied that require on-site measurements (Barthelmie et al., 2002). Oh et al., (2012a) used data measured from three meteorological masts in Korea for assessing the long-term potential of wind power in this country. In another study by Oh et al. (2012b), the authors analyzed marine buoy datasets measured at 5 positions over a period of 12 years and satellite data over 9 years as well as a numerical wind map based on climatological data obtained for 4 years for estimation of the offshore wind potential in Korea. Lee et al. (2013) assessed the potential of the offshore wind power at Younggwang in Korea via the Weibull model that has been fitted based on the measured data and estimated parameters. Kempton et al. (2007) used buoy data to assess the offshore wind potential along the US East Coast.

\section{B. Tools and methods for assessing flexibility and sustainability aspects}

\section{Optimization method}

According to Subramanian and Ramanathan (2012), multi-criteria decision making has been utilized in different decision areas: operation strategy, product and process design, planning and scheduling resources, project management, and supply chain. The main objective of the multi-criteria decision making $(\mathrm{MCDM})$ method is the selection of the most preferred 
alternative for decision makers involved in the problem. There are certain steps in applying the MCDM method. First of all, there is a definition of the crucial criteria related to the goal and the problem context. The next step consists of defining the alternatives and evaluation of these alternatives based on the criteria. Applying the multi-criteria analysis method and finding the preferred solution are the last steps of the method. Wu et al. (2016) used ELECTRE-III in a fuzzy environment for developing a decision framework for finding the best sites for the offshore wind energy in China. Fetanat and Khorasaninejad (2015) developed a model using fuzzy Analytical Network Process (ANP), fuzzy decision-making trial, and evaluation laboratory and ELECTRE for site selection of the offshore wind energy in Iran. Jongbloed et al. (2014) and Schillings et al. (2012) used decision support systems for evaluating the potential of offshore wind energy in North Sea.

Optimization models usually use minimization of the cost or maximization of the energy generated for site selection or wind farm layout planning. However, the different criteria could be integrated into the model to provide a complete analysis. Gao et al. (2014) developed an optimization model using the Multi-Population Genetic Algorithm for assessing the potential of the offshore wind energy in Hong Kong for obtaining a minimum cost of energy and maximum power generation. Kim et al. (2013) used rating indices for selection of the optimum sites in the Korean Peninsula considering the benefit/cost ratio, installation capacity, and convenience of the grid for each potential site.

\section{CONCLUSION AND DISCUSSION}

This paper provides a literature review of offshore wind energy potential assessment approaches that were published in the 2000-2016 period. Academics and practitioners may find this research valuable because it summarizes the different approaches for evaluating offshore wind energy capacity, market deployment, and key parameters. Highlights of this study include the critical factors for estimation of offshore wind energy and the methods used. Eight categories of factors, technical, geographical, economic, social, environmental, market, policy, and technology evolution, are considered in the context of the references. The applied methods for estimation of the theoretical potential, technical, economic, and decision-making analysis are discussed.

The results of the systematic review indicate the following issues:

- The number of studies that analyze the European offshore wind energy potential is two times the studies that cover the worldwide view. The policy making in renewable energy particularly in offshore wind energy in Europe plays a critical role in stimulating the research in this field. There is a need to analyze the worldwide potential for offshore wind energy from an integrated perspective including feasibility, sustainability, and flexibility aspects. Arent et al. (2012) also emphasized the need of more precise offshore wind potential estimation as an essential element of continuing climate mitigation scenario analysis and the influential role in the energy mix results and the economic study of mitigation opportunities. The authors clarified that the improvement in methodologies and input parameters that consider geospatial economics and variability are the needs for future research.

- The feasibility study based on offshore wind resources and technical and spatial constraints is the first step of the potential assessment. Some studies focused on this part profoundly via statistical analysis or climatological simulation models. The potential worldwide analysis based on all geographic and spatial constraints is challenging via the lack of a detailed database. For example, considering shipping lanes and maritime traffic in the analyses is restricted due to the limitations of the databases. The exclusion of the protected areas and the distance from shore are diverse in the studies because of the different standards, policies, regulations, as well as the availability of data.

- The sustainability of the estimated potential could be achieved by adding the economic, social, and environmental factors. However, there are few studies that address sustainability via real data. The socio-economic analysis of the offshore wind farms should be done based on the detailed information of a specific region. The environmental data are also limited. The cost 
estimation of the offshore wind farm also requires addressing the appropriate parameters and data to reveal a realistic estimation. However, the cost function that was considered in the studies principally focused on the capital and operation costs as a function of the distance from the shore and water depth.

- The robustness of the potential assessment should be considered via integrating market analysis, policy changes, and technology evolutions into the previous studies. Considering these aspects is sparse in the literature. There are few studies that considered feed in tariff as an input parameter for scenario planning. However, the other short and long-term policies in building a highly skilled workforce, providing market confidence and demand visibility, building competitive supply chain, and supporting innovation should be considered.

- From a methodological point of view, the survey of the articles shows that an assimilation of the different methods as a hybrid method is needed to provide an optimum and realistic potential offshore wind energy estimation.

We excluded the references that performed life cycle assessment of offshore wind energy in this literature review as these studies mainly only focused on the ecological impacts of the wind farm development. In this study, we principally focused on the studies that aim to assess the potential of offshore wind energy considering the different social, economic, environmental, or other restrictions. However, using the outcomes of the LCA studies in developing research that assesses the mitigation and adaptation of offshore wind energy planning is valuable. Performing a systematic literature review on LCA of offshore wind energy and linking the outcomes to the assessment of the potential deployment considering the other technical, social, and economic factors are suggested as the future research.

Ackermann, T., Leutz, R., and Hobohm, J., "Worldwide offshore wind potential and European projects," in Power Engineering Society Summer Meeting, 2001 (IEEE, 2001), Vol. 1, pp. 4-9.

Archer, C. L. and Jacobson, M. Z., "Geographical and seasonal variability of the global 'practical' wind resources," Appl. Geogr. 45, 119-130 (2013).

Arent, D., Sullivan, P., Heimiller, D., Lopez, A., Eurek, K., Badger, J., Jørgensen, H. E., Kelly, M., Clarke, L., and Luckow, P., "Improved offshore wind resource assessment in global climate stabilization scenarios," Contract 303, 275-3000 (2012).

Asdrubali, F., Baldinelli, G., D’Alessandro, F., and Scrucca, F., "Life cycle assessment of electricity production from renewable energies: Review and results harmonization,” Renewable Sustainable Energy Rev. 42, 1113-1122 (2015).

Asif, M. and Muneer, T., "Energy supply, its demand and security issues for developed and emerging economies," Renewable Sustainable Energy Rev. 11(7), 1388-1413 (2007).

Barthelmie, R. J., Frandsen, S., Pryor, S., Morgan, C., Henderson, A., Surrensen, H. C., et al., "Offshore wind potential in Europe and review of offshore resource modeling techniques," in Offshore Wind Energy (CD-ROM) (2002).

Bonou, A., Laurent, A., and Olsen, S. I., "Life cycle assessment of onshore and offshore wind energy-from theory to application," Appl. Energy 180, 327-337 (2016).

Breton, S. P. and Moe, G., "Status, plans and technologies for offshore wind turbines in Europe and North America," Renewable Energy 34(3), 646-654 (2009).

Chiang, E. P., Zainal, Z. A., Narayana, A., and Seetharamu, K. N., Potential of Renewable Wave and Offshore Wind Energy Sources in Malaysia, Marine Technology 2003 Seminar (2003).

Dvorak, M. J., Archer, C. L., and Jacobson, M. Z., "California offshore wind energy potential," Renewable Energy 35(6), 1244-1254 (2010).

Elliot, D., Frame, C., Gill, C., Hanson, H., Moriarty, P., Powell, M., et al., "Offshore resource assessment and design conditions: A data requirements and gaps analysis for offshore renewable energy systems," Technical Report No. DOE/EE0696, US Department of Energy, Washington, DC, USA (2012).

Esteban, M. D., Diez, J. J., López, J. S., and Negro, V., “Why offshore wind energy?,” Renewable Energy 36(2), 444-450 (2011).

Fehrenbacher, K., http://fortune.com/2016/08/08/first-us-offshore-wind/ for This Is Where the First U.S. Offshore Wind Turbines Were Just Installed, Tech Future of Work, 2016.

Fetanat, A. and Khorasaninejad, E., "A novel hybrid MCDM approach for offshore wind farm site selection: A case study of Iran,” Ocean Coastal Manage. 109, 17-28 (2015).

Finkbeiner, M., Schau, E. M., Lehmann, A., and Traverso, M., "Towards life cycle sustainability assessment," Sustainability 2(10), 3309-3322 (2010)

Gao, X., Yang, H., and Lu, L., "Study on offshore wind power potential and wind farm optimization in Hong Kong," Appl. Energy 130, 519-531 (2014).

Garrett, P. and Rønde, K., "Life cycle assessment of wind power: Comprehensive results from a state-of-the-art approach," Int. J. Life Cycle Assess. 18(1), 37-48 (2013).

Govindji, Al., James, R., and Carvallo, A., https://www.carbontrust.com/media/566323/ctc834-detailed-appraisal-of-theoffshore-wind-industry-in-japan.pdf for Appraisal of the Offshore Wind Industry in Japan, Carbon Trust; accessed 16 February 2017, 2014. 
Guezuraga, B., Zauner, R., and Pölz, W., "Life cycle assessment of two different 2 MW class wind turbines," Renewable Energy 37(1), 37-44 (2012).

Guidelines for Social Life Cycle Assessment of Products, edited by Benoit, C. (UNEP/Earthprint, 2010).

Hauschild, M. Z., "Assessing environmental impacts in a life-cycle perspective," Environ. Sci. Technol. 39(4), 81A-88A (2005).

Henderson, A. R., Morgan, C., Smith, B., Sørensen, H. C., Barthelmie, R. J., and Boesmans, B., "Offshore wind energy in Europe-A review of the state-of-the-art," Wind Energy 6(1), 35-52 (2003).

Higgins, P. and Foley, A., "The evolution of offshore wind power in the United Kingdom," Renewable Sustainable Energy Rev. 37, 599-612 (2014).

Hong, L. and Möller, B., "Offshore wind energy potential in China: Under technical, spatial and economic constraints," Energy 36(7), 4482-4491 (2011).

Hoogwijk, M. and Graus, W., "Global potential of renewable energy sources: A literature assessment. Background report prepared by order of REN21," Ecofys, Report No. PECSNL072975, 2008.

Hoogwijk, M., de Vries, B., and Turkenburg, W., "Assessment of the global and regional geographical, technical and economic potential of onshore wind energy," Energy Econ. 26(5), 889-919 (2004).

Investopedia, http://www.investopedia.com/terms/d/discountrate.asp for Discount rate definition; accessed 8 August 2017.

Jacobson, M. Z., "Review of solutions to global warming, air pollution, and energy security," Energy Environ. Sci. 2(2), $148-173$ (2009).

Jongbloed, R. H., van der Wal, J. T., and Lindeboom, H. J., "Identifying space for offshore wind energy in the North Sea. Consequences of scenario calculations for interactions with other marine uses," Energy Policy 68, 320-333 (2014).

Kaldellis, J. K., "Social attitude towards wind energy applications in Greece," Energy Policy 33(5), 595-602 (2005).

Karlsson, K., Mischke, P., Miketa, A., and Wagner, N. W., "Global energy perspectives with an emphasis on wind energy," in Dtu International Energy Report 2014 (Technical University of Denmark, 2014).

Kempton, W., Archer, C. L., Dhanju, A., Garvine, R. W., and Jacobson, M. Z., "Large $\mathrm{CO}_{2}$ reductions via offshore wind power matched to inherent storage in energy end-uses," Geophys. Res. Lett. 34(2), L02817, https://doi.org/10.1029/ 2006GL028016 (2007).

Kim, H. C., Fthenakis, V., Choi, J.-K., and Turney, D. E., "Life cycle greenhouse gas emissions of thin-film, photovoltaic electricity generation," J. Ind. Ecol. 16, S110-S121 (2012).

Kim, J. Y., Oh, K. Y., Kang, K. S., and Lee, J. S., "Site selection of offshore wind farms around the Korean Peninsula through economic evaluation," Renewable Energy 54, 189-195 (2013).

Lee, M. E., Kim, G., Jeong, S. T., Ko, D. H., and Kang, K. S., "Assessment of offshore wind energy at Younggwang in Korea," Renewable Sustainable Energy Rev. 21, 131-141 (2013).

Levitt, A. C., Kempton, W., Smith, A. P., Musial, W., and Firestone, J., "Pricing offshore wind power," Energy Policy 39(10), 6408-6421 (2011).

Li, C. B., Chen, H. Y., Zhu, J., Zuo, J., Zillante, G., and Zhao, Z. Y., "Comprehensive assessment of flexibility of the wind power industry chain," Renewable Energy 74, 18-26 (2015).

Li, G., "Feasibility of large-scale offshore wind power for Hong Kong-A preliminary study," Renewable Energy 21(3), 387-402 (2000).

Lu, X., McElroy, M. B., and Kiviluoma, J., "Global potential for wind-generated electricity," Proc. Natl. Acad. Sci. 106(27), 10933-10938 (2009).

Mesoscale Model, http://www.hko.gov.hk/nhm/mesomodel_e.htm for HKO Center; accessed 16 February 2017 (2015).

Möller, B., "Continuous spatial modeling to analyze planning and economic consequences of offshore wind energy," Energy Policy 39(2), 511-517 (2011).

Möller, B., Hong, L., Lonsing, R., and Hvelplund, F., "Evaluation of offshore wind resources by the scale of development," Energy 48(1), 314-322 (2012).

Mostafaeipour, A., "Feasibility study of offshore wind turbine installation in Iran compared with the world," Renewable Sustainable Energy Rev. 14(7), 1722-1743 (2010).

Musial, W. and Butterfield, S., "Future for offshore wind energy in the United States," in EnergyOcean 2004 Conference (2004), pp. 4-6.

Norris, G. A., "Social impacts in product life cycles-towards life cycle attribute assessment," Int. J. Life Cycle Assess. 11(1), 97-104 (2006)

Oh, K. Y., Kim, J. Y., Lee, J. K., Ryu, M. S., and Lee, J. S., "An assessment of wind energy potential at the demonstration offshore winds farm in Korea," Energy 46(1), 555-563 (2012a).

Oh, K. Y., Kim, J. Y., Lee, J. S., and Ryu, K. W., "Wind resource assessment around Korean Peninsula for a feasibility study on 100 MW class offshore wind farm," Renewable Energy 42, 217-226 (2012b).

O'Keeffe, A. and Haggett, C., "An investigation into the potential barriers facing the development of offshore wind energy in Scotland: Case study-Firth of Forth offshore wind farm," Renewable Sustainable Energy Rev. 16(6), 3711-3721 (2012).

Rodrigues, S., Restrepo, C., Kontos, E., Pinto, R. T., and Bauer, P., "Trends in offshore wind projects," Renewable Sustainable Energy Rev. 49, 1114-1135 (2015).

Rousseau, D. M., Manning, J., and Denyer, D., "11 evidence in management and organizational science: Assembling the field's full weight of scientific knowledge through syntheses," Acad. Manage. Ann. 2(1), 475-515 (2008).

Schillings, C., Wanderer, T., Cameron, L., van der Wal, J. T., Jacquemin, J., and Veum, K., "A decision support system for assessing offshore wind energy potential in the North Sea," Energy Policy 49, 541-551 (2012).

Schwägerl, Ch., https://www.theguardian.com/environment/2016/oct/20/europes-offshore-wind-industry-booming-ascosts-fall for Europes-offshore-wind-industry-booming-as-costs-fall; accessed 1 June 2017 (2016).

Schwartz, M., Heimiller, D., Haymes, S., and Musial, W., "Assessment of offshore wind energy resources for the United States," National Renewable Energy Laboratory, Golden, CO, Technical Report No. NREL/TP-500-45889, 2010.

See http://www.businessdictionary.com/definition/economic-sustainability.html for "Economic Sustainability, In Business Dictionary"; accessed 16 February 2017.

See http://www.globalwindatlas.com/ for Global Wind Atlas; accessed 16 February 2017. 
See http://www.gwec.net/wp-content/uploads/2015/03/GWEC_Global_Wind_2014_Report_LR.pdf for Global Wind Report Annual Market; accessed 16 February 2017, 2014.

See http://www.lorc.dk/offshore-wind-farms-map for List of Offshore Wind Farms; accessed 16 February 2017.

See https://www.boem.gov/Renewable-Energy-Program/Renewable-Energy-Guide/Offshore-Wind-Energy.aspx for Offshore Wind Energy; accessed 16 February 2017.

See http://www.gwec.net/wp-content/uploads/2015/06/prefeasabilityTN.pdf for Pre-Feasibility Study for Offshore Wind Farm Development in Tamil Nadu; accessed 16 February 2017 (2015).

See https://phys.org/news/2014-03-hydro-storage-solution-renewables.html for Pumped hydro offers storage solution for renewables; accessed 16 February 2017 (2014).

See http://www.gwec.net/global-figures/wind-in-numbers/ for Wind in Numbers; accessed 16 February 2017.

Snyder, B. and Kaiser, M. J., "A comparison of offshore wind power development in Europe and the US: Patterns and drivers of development," Appl. Energy 86(10), 1845-1856 (2009a).

Snyder, B. and Kaiser, M. J., "Ecological and economic cost-benefit analysis of offshore wind energy," Renewable Energy 34(6), 1567-1578 (2009b).

Subramanian, N. and Ramanathan, R., "A review of applications of analytic hierarchy process in operations management," Int. J. Prod. Econ. 138(2), 215-241 (2012).

Sun, X., Huang, D., and Wu, G., "The current state of offshore wind energy technology development," Energy 41(1), 298-312 (2012).

Swarr, T. E., "Societal life cycle assessment—could you repeat the question?," Int. J. Life Cycle Assess. 14(4), 285-289 (2009).

Swart, R. J., Coppens, C., Gordijn, H., Piek, M., Ruyssenaars, P., Schrander, J. J., et al., Europe's Onshore and Offshore Wind Energy Potential: An Assessment of Environmental and Economic Constraints (European Environment Agency, 2009), p. 90.

Tranfield, D., Denyer, D., and Smart, P., "Towards a methodology for developing evidence-informed management knowledge by means of systematic review," Br. J. Manage. 14(3), 207-222 (2003).

Vázquez-Carrasco, R. and López-Pérez, M. E. "Small \& medium-sized enterprises and corporate social responsibility: A systematic review of the literature," Qual. Quant. 47(6), 3205-3218 (2013).

Vincent, C. L., Draxl, C., and Nielsen, J. R., https://www.windpower.org/download/559/1_mesoscale_modelling_safetypdf for "Mesoscale meteorological models, National Laboratory for sustainable energy, DTU; accessed 8 August 2017.

WRF, http://www.wrf-model.org/index.php for The Weather Research and Forecasting Model; accessed 8 August 2017.

Wu, Y., Zhang, J., Yuan, J., Geng, S., and Zhang, H., "Study of decision framework of offshore wind power station site selection based on ELECTRE-III under intuitionistic fuzzy environment: A case of China," Energy Convers. Manage. 113, 66-81 (2016).

Wüstenhagen, R., Wolsink, M., and Bürer, M. J., "Social acceptance of renewable energy innovation: An introduction to the concept," Energy Policy 35(5), 2683-2691 (2007).

Yamaguchi, A., Ishihara, T., and Fujino, Y., "An assessment of offshore wind energy potential using mesoscale model and GIS," in Proceedings of European Wind Energy Conference (2004).

Yi, H. and Feiock, R. C., "Renewable energy politics: Policy typologies, policy tools, and state deployment of renewables," Policy Stud. J. 42(3), 391-415 (2014).

Zhang, H., Li, L., Zhou, D., and Zhou, P., "Political connections, government subsidies, and firm financial performance: Evidence from renewable energy manufacturing in China," Renewable Energy 63, 330-336 (2014).

Zhao, Z. Y., Zhu, J., and Zuo, J., "The flexibility of wind power industry chain for environmental turbulence: A matching model study," Renewable Energy 83, 375-383 (2015).

Zhixin, W., Chuanwen, J., Qian, A., and Chengmin, W., "The key technology of offshore wind farm and its new development in China," Renewable Sustainable Energy Rev. 13(1), 216-222 (2009). 